Research Article

\title{
Detection Efficiency of NaI(Tl) Detector in 511-1332 keV Energy Range
}

\author{
I. Akkurt, ${ }^{1}$ K. Gunoglu, ${ }^{2}$ and S. S. Arda ${ }^{1}$ \\ ${ }^{1}$ Fen-Edebiyat Fakultesi Fizik Bol, Suleyman Demirel University, 32260 Isparta, Turkey \\ ${ }^{2}$ Teknşk Bil. MYO, Suleyman Demirel University, 32260 Isparta, Turkey \\ Correspondence should be addressed to I. Akkurt; iskenderakkurt@sdu.edu.tr
}

Received 13 August 2013; Revised 9 December 2013; Accepted 15 December 2013; Published 12 March 2014

Academic Editor: Jakrapong Kaewkhao

Copyright (c) 2014 I. Akkurt et al. This is an open access article distributed under the Creative Commons Attribution License, which permits unrestricted use, distribution, and reproduction in any medium, provided the original work is properly cited.

As it is important to obtain accurate analytical result in an experimental research, this required quality control of the experimental system. Gamma spectrometry system can be used in a variety of different fields such as radiation and medical physics. In this paper the absolute efficiency, peak to valley ratio, and energy resolution of a $3^{\prime \prime} \times 3^{\prime \prime} \mathrm{NaI}(\mathrm{Tl})$ detector were determined experimentally for $511,662,835,1173,1275$, and $1332 \mathrm{keV}$ photon energies obtained from ${ }^{22} \mathrm{Na},{ }^{54} \mathrm{Mn},{ }^{60} \mathrm{Co}$, and ${ }^{137} \mathrm{Cs}$ radioactive sources.

\section{Introduction}

With the start of using radioactive sources in a variety of different fields such as health physics, industry, energy, and environmental application nuclear radiation detectors become the most fundamental instruments as radiation is hazardous for health. In a radiation measurement an accurate knowledge of the detector spectral performance is required. As the radiation can travel large distances between the interactions in the detector material before detection is possible, the detectors do not have $100 \%$ efficiency. In the radiation measurement, one of the most important characteristics of a detector is the efficiency of the detector. Gamma spectrometry is one of the most widely used detector systems in this field and its performance directly depends on the knowledge of the detection efficiency. The detection efficiency is a measure of the percentage of radiation that a given detector detects from the overall yield emitted from the source. It can vary with the volume and shape of the detector material, absorption cross-section in the material, attenuation layers in front of the detector, and distance and position from the source to the detector [1].

Detection efficiency of a detector system depends on different parameters and thus various kinds of the efficiency definitions are used to cover those parameters. (i) Absolute efficiency: it is the ratio of the number of counts recorded by the detector to the number of gamma rays emitted by the source (in all directions).

(ii) Intrinsic efficiency: it is the ratio of the number of pulses recorded by the detector to the number of gamma rays hitting the detector.

(iii) Full-energy peak (or photopeak) efficiency: it is the efficiency for producing full-energy peak pulses only, rather than a pulse of any size, for the gamma ray.

Especially in the radioactivity measurement the absolute efficiency of the detector must be known. It is defined as the ratio of the number of counts recorded by the detector $\left(N_{c}\right)$ to the number of radiation $\left(N_{s}\right)$ emitted by the source (in all directions) as represented in the following formula:

$$
\varepsilon_{\mathrm{abs}}=\frac{N_{c}}{N_{s}} .
$$

Absolute efficiency of the detector depends not only on detector properties but also on the details of the counting geometry.

Various experimental and calculation works have been reported for the detection efficiency work [2-6]. 


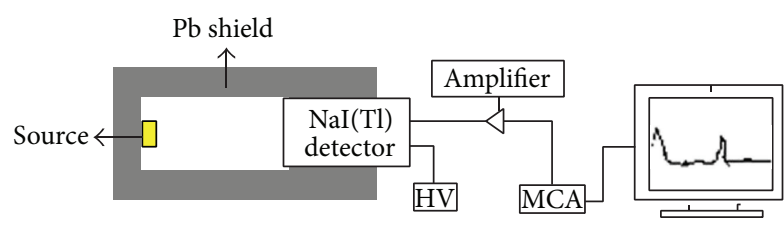

FIgURE 1: Schematic view of the experimental system.

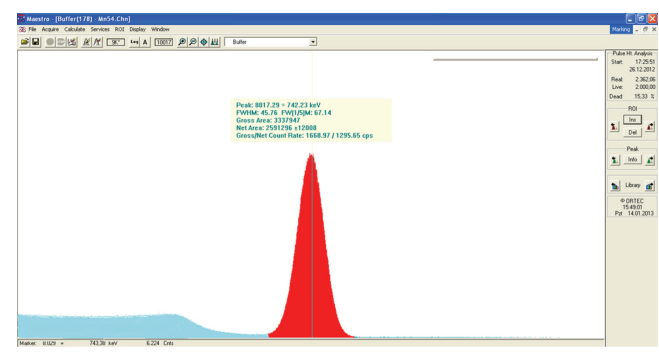

FIGURE 2: Gamma ray spectrum obtained from ${ }^{137}$ Cs source.

TABLE 1: The present activity and half-life of the radioactive sources used to obtain energies.

\begin{tabular}{lcc}
\hline Nuclide & Activity (micro Ci) & Half-life (day) \\
\hline${ }^{22} \mathrm{Na}$ & 0.706 & 950.8 \\
${ }^{54} \mathrm{Mn}$ & 0.348 & 312.3 \\
${ }^{137} \mathrm{Cs}$ & 0.970 & 11020.0 \\
${ }^{60} \mathrm{Co}$ & 0.843 & 1925.5 \\
\hline
\end{tabular}

For the gamma ray spectrometry, the absolute efficiency and energy resolution are important parameters to be determined. Those parameters are usually done using a function to fit the efficiency at a wide energies range, as the number of energy peaks obtained from radioactive sources is limited. For these purposes the absolute efficiency and the energy resolution of the $\mathrm{NaI}(\mathrm{Tl})$ detector have been determined experimentally at $511,662,835,1173,1275$, and $1332 \mathrm{keV}$ energies obtained from ${ }^{22} \mathrm{Na},{ }^{54} \mathrm{Mn},{ }^{60} \mathrm{Co}$, and ${ }^{137} \mathrm{Cs}$ radioactive isotopes.

\section{Experimental Methods}

The gamma ray spectrometry consists of a $3 \times 3^{\prime \prime} \mathrm{NaI}(\mathrm{Tl})$ detector and this is connected to 16384-channel Multichannel Analyser (MCA). The spectrum obtained from MCA is analyzed using the Genie 2 software obtained from Canberra [7-9]. In order to reduce the background level of the system, the detector is shielded using $6 \mathrm{~cm}$ lead on all sides. A schematic view of the system has been displayed in Figure 1. The 4 different radiation sources $\left({ }^{22} \mathrm{Na},{ }^{54} \mathrm{Mn},{ }^{60} \mathrm{Co}\right.$, and $\left.{ }^{137} \mathrm{Cs}\right)$ that give $511,662,835,1173,1275$, and $1332 \mathrm{keV}$ gamma ray energy were placed at 5 different distances $(0,5,1,3,5$, and $10 \mathrm{~cm}$ ) from the face of detector and the measurement has been performed for each source. Each measurement has been done for a period of $60 \mathrm{~min}$ to obtain good statistics in the evaluation of each gamma peak. Typical gamma ray spectrum for ${ }^{137} \mathrm{Cs}$ and ${ }^{60} \mathrm{Co}$ sources taken with the $\mathrm{NaI}(\mathrm{Tl})$ detector is given in Figures 2 and 3. In Table 1 the present activity

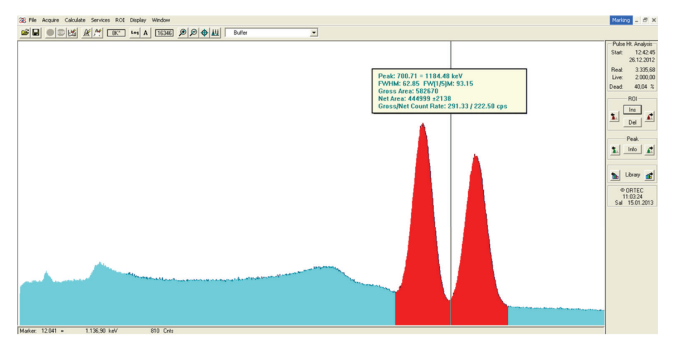

Figure 3: Gamma ray spectrum obtained from ${ }^{60}$ Co source.

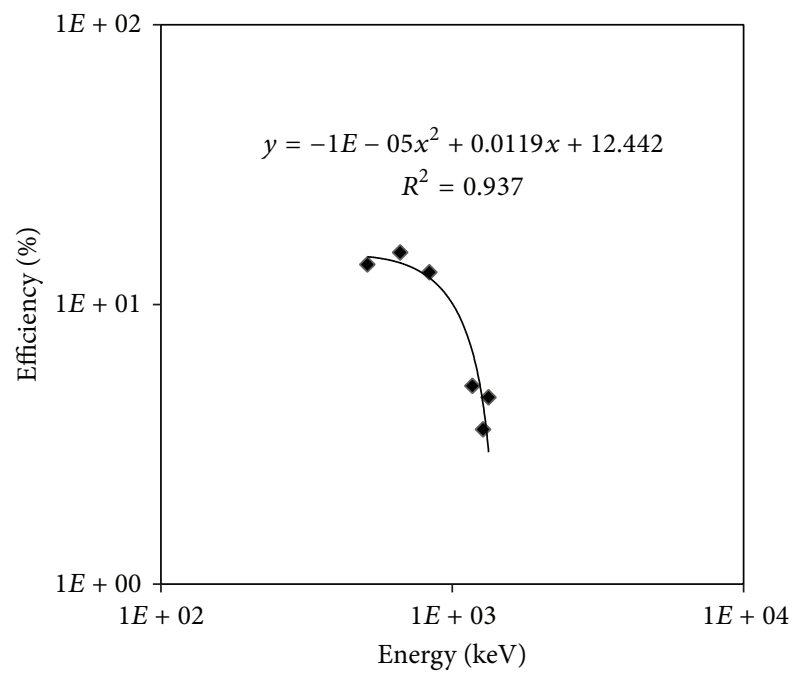

FIgURE 4: Detection efficiency of $\mathrm{NaI}(\mathrm{Tl})$ detector as a function of gamma ray energies (source placed at $0,5 \mathrm{~cm}$ distance to the detector face).

TABLE 2: The energies and emission probabilities of the radioisotope source [11].

\begin{tabular}{lcc}
\hline Nuclide & Energy $(\mathrm{keV})$ & Emission probability (\%) \\
\hline${ }^{22} \mathrm{Na}$ & 511.00 & 178.00 \\
& 1274.60 & 99.94 \\
${ }^{54} \mathrm{Mn}$ & 834.83 & 85.59 \\
${ }^{137} \mathrm{Cs}$ & 661.66 & 85.30 \\
& 1173.23 & 99.85 \\
${ }^{60} \mathrm{Co}$ & 1332.48 & 99.98 \\
\hline
\end{tabular}

and half-life of the radioisotope sources are given and in Table 2 the energies and emission probabilities of the radioisotope source are given.

\section{Results and Discussions}

The properties such as detector efficiency, energy calibration, and energy resolution of a $\mathrm{NaI}(\mathrm{Tl})$ detector have been measured for 6 different gamma ray energies.

3.1. Efficiency Calibrations. The detection efficiency of the $\mathrm{NaI}(\mathrm{Tl})$ detector was obtained using (1) for each gamma ray energy emitted by the ${ }^{22} \mathrm{Na},{ }^{54} \mathrm{Mn},{ }^{60} \mathrm{Co}$, and ${ }^{137} \mathrm{Cs}$ radioactive 

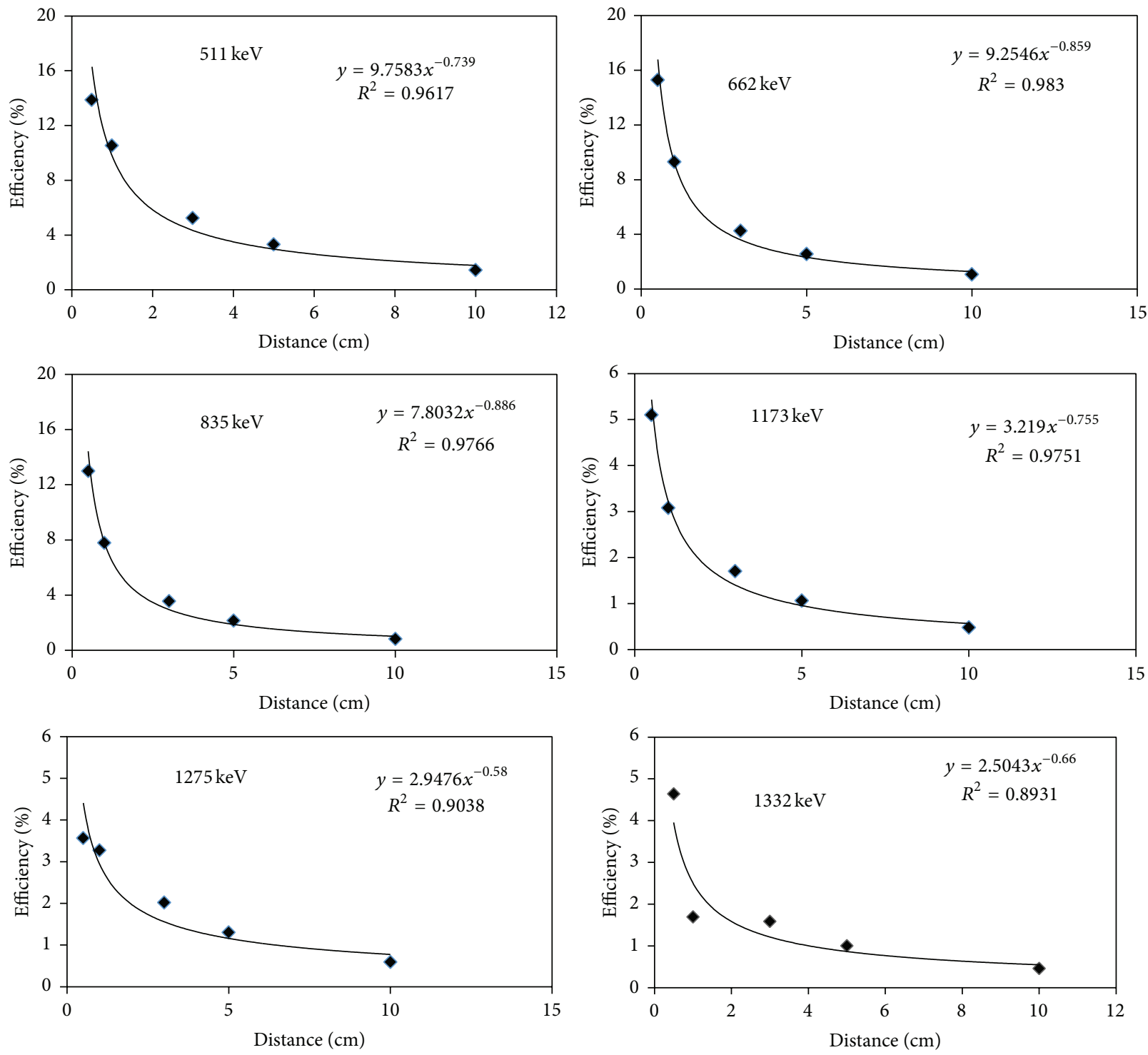

FIGURE 5: Variation of detection efficiency of $\mathrm{NaI}(\mathrm{Tl})$ detector as a function of distance.

isotopes. The obtained results have been displayed as a function of gamma ray energy in Figure 4. As can be seen from this figure, there is a great variety of analytical functions that is used to describe the efficiency dependence on the energy. The solid line represents a second degree polynomial fit that gives a good description with the correlation coefficient between the efficiency values and the gamma ray energies, which is about $R^{2}=0,94$.

As the detection efficiency of the $\mathrm{NaI}(\mathrm{Tl})$ detector can vary with the distance to the detector face, the efficiencies have been obtained for 5 different distances from the detector. The results are displayed in Figure 5 for 5 different distances and 6 different energies. It can be seen from this figure that the detection efficiency has decreased exponentially with the increasing distance from detector face.

The obtained results have been compared with the calculation obtained using the same detector size [10].
The comparisons have been displayed in Figures 6 and 7 where 0.5 and $10 \mathrm{~cm}$ distances have been used. A good agreement between experimental and calculated results was obtained as can be seen from these figures.

3.2. Energy Calibrations and Resolution. The detector system should be calibrated before using in radiation detection in order to covert channel number to energy scale. This is carried out under laboratory conditions that mimic as closely as possible the experimental conditions. Several radioactive sources (at least 3 different energy peaks) are used to get certain peak to see channel number. This is usually done using ${ }^{137} \mathrm{Cs}$ and ${ }^{60} \mathrm{Co}$ radioactive sources as they produce $\gamma$-ray energy of 662,1170 , and $1332 \mathrm{keV}$, respectively. In Figure 8 the $\gamma$-ray spectrum obtained from those sources and related fit has been displayed. 


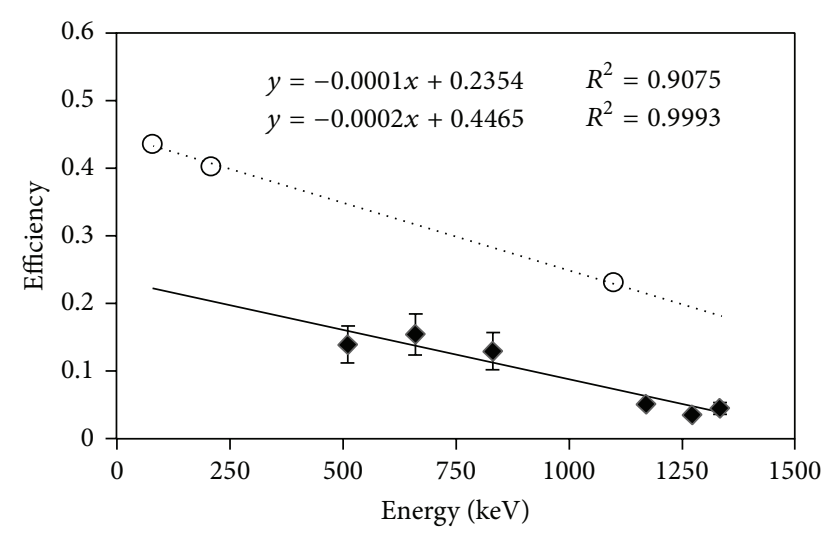

- Present data

Y Yalcin et al.

Figure 6: Comparison of measured and calculated detection efficiency of $\mathrm{NaI}(\mathrm{Tl})$ detector (source placed at $0,5 \mathrm{~cm}$ distance to the detector face).

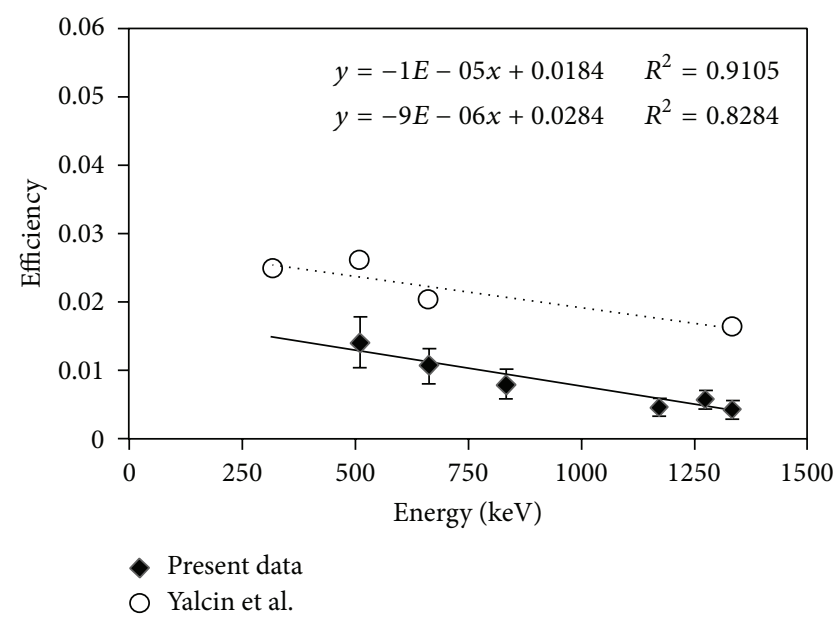

Figure 7: Comparison of measured and calculated detection efficiency of $\mathrm{NaI}(\mathrm{Tl})$ detector (source placed at $10 \mathrm{~cm}$ distance to the detector face).

The energy resolution of a detector system is obtained from the peak full width at one-half of the maximum height (FWHM) of a single peak using the following equation:

$$
R=\frac{\mathrm{FWHM}}{E_{o}} \times 100
$$

Here $R$ is energy resolution and $E_{o}$ is the related energy. It will provide the separation for two adjacent energy peaks which will lead to identification of different nuclide in spectrum. The measured energy resolution of the $\mathrm{NaI}(\mathrm{Tl})$ detector is displayed in Figure 9 as a function of gamma ray energy. It can be seen from this figure that the energy resolution of the $\mathrm{NaI}(\mathrm{Tl})$ detector decreased with the FWHM with the increasing gamma ray energy.

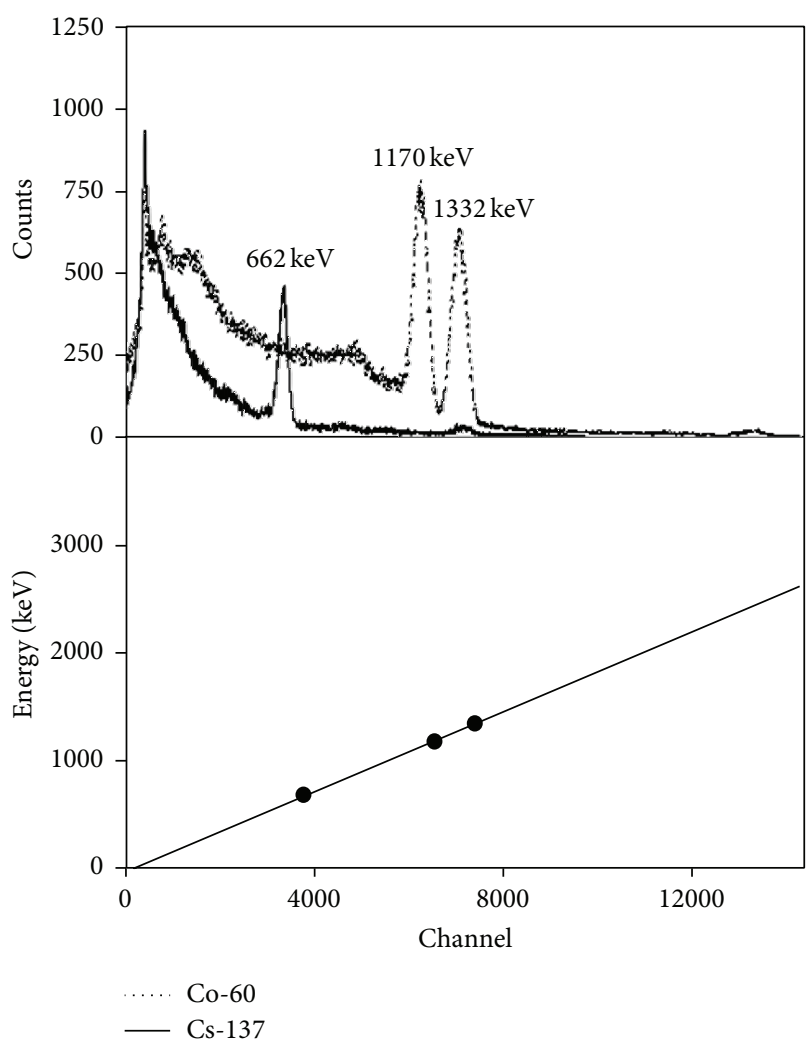

Figure 8: Energy spectrum and calibration fit for ${ }^{137} \mathrm{Cs}$ and ${ }^{60} \mathrm{Co}$ sources.

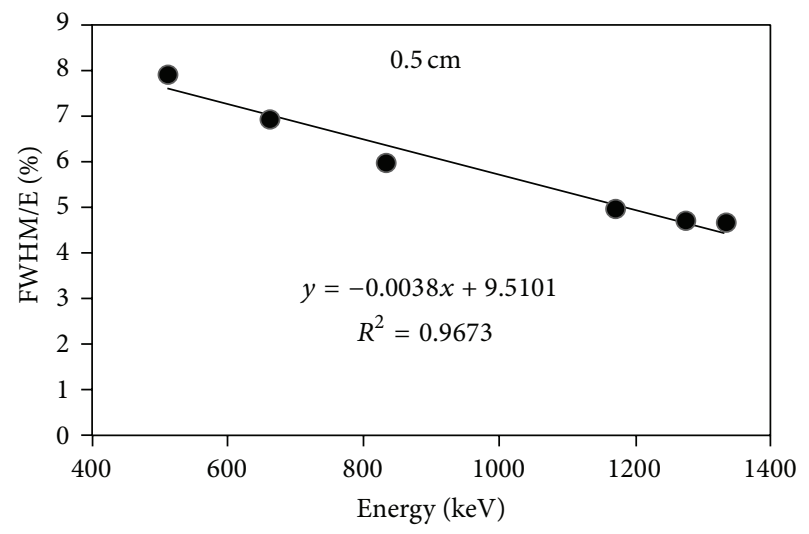

FIGURE 9: Energy resolution of the $\mathrm{NaI}(\mathrm{Tl})$ detector obtained for $0,5 \mathrm{~cm}$ distance.

\section{Conclusions}

The detection efficiency and energy resolution for the $\mathrm{NaI}(\mathrm{Tl})$ scintillation detectors were measured. The variation of detection efficiency with the gamma ray energy and detection distance was also investigated. It was found from this work that the detection efficiency depends on gamma ray energy and also source distance to the detector. 


\section{Conflict of Interests}

The authors declare that there is no conflict of interests regarding the publication of this paper.

\section{Acknowledgments}

This work has been supported partly by the Suleyman Demirel University Foundation Unit (3312-YL2-12) and partly by the State Planning Unit (DPT2006K-120470) in Turkey.

\section{References}

[1] K. Debertin and R. G. Helmer, Gamma- and X-Ray Spectrometry with Semiconductor Detectors, North-Holland, 1988.

[2] L. Zikovsky and B. Chah, "A computer program for calculating $\mathrm{Ge}(\mathrm{Li})$ detector counting efficiencies with large volume samples," Nuclear Instruments and Methods in Physics Research A, vol. 263, no. 2-3, pp. 483-486, 1988.

[3] Y. S. Selim, M. I. Abbas, and M. A. Fawzy, "Analytical calculation of the efficiencies of gamma scintillators-part I: total efficiency for coaxial disk sources," Radiation Physics and Chemistry, vol. 53, no. 6, pp. 589-592, 1998.

[4] A. Jehouani, R. Ichaoui, and M. Boulkheir, "Study of the NaI(Tl) efficiency by Monte Carlo method," Applied Radiation and Isotopes, vol. 53, no. 4-5, pp. 887-891, 2000.

[5] M. I. Abbas, "Analytical formulae for well-type NaI (Tl) and HPGe detectors efficiency computation," Applied Radiation and Isotopes, vol. 55, no. 2, pp. 245-252, 2001.

[6] A. Gültekin, G. Kaynak, and O. Gürler, "Determination of full energy peak efficiency of HpGe detector from 59.5 to 1332.5 keV,' Indian Journal of Pure and Applied Physics, vol. 44, no. 4, pp. 281-286, 2006.

[7] I. Akkurt and H. Akyıldırım, "Radiation transmission of concrete including pumice for 662, 1173 and $1332 \mathrm{keV}$ gamma rays," Nuclear Engineering and Design, vol. 252, pp. 163-166, 2012.

[8] I. Akkurt and A. Alkhayatt, "The effect of barite proportion on neutron and gamma-ray shielding," Annals of Nuclear Energy, vol. 51, pp. 5-9, 2013.

[9] B. Mavi and I. Akkurt, "Natural radioactivity and radiation hazards in some building materials used in Isparta, Turkey," Radiation Physics and Chemistry, vol. 79, no. 9, pp. 933-937, 2010.

[10] S. Yalcin, O. Gurler, G. Kaynak, and O. Gundogdu, "Calculation of total counting efficiency of a $\mathrm{NaI}(\mathrm{Tl})$ detector by hybrid Monte-Carlo method for point and disk sources," Applied Radiation and Isotopes, vol. 65, no. 10, pp. 1179-1186, 2007.

[11] R. B. Firestone and L. P. Ekström, "Table of Radioactive Isotopes; Database Version 2.1.," 2004, http://ie.lbl.gov/toi/. 


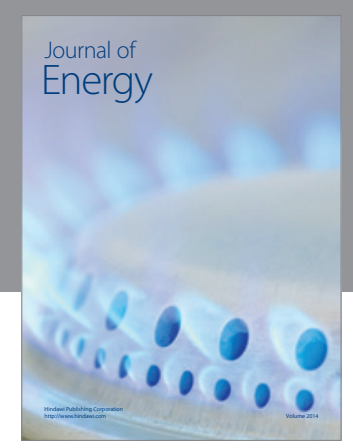

Journal of

Industrial Engineering
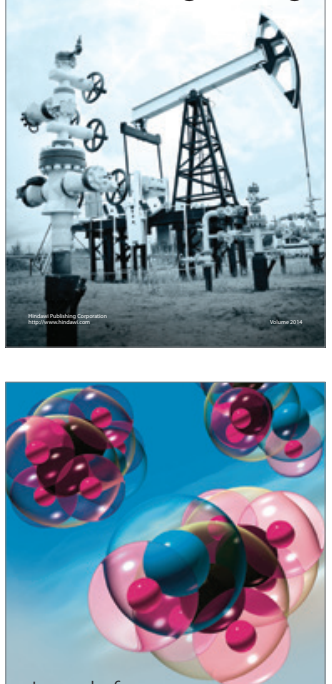

Fuels
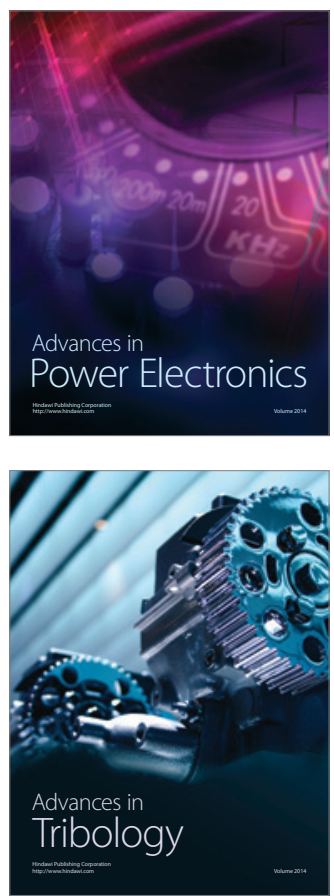

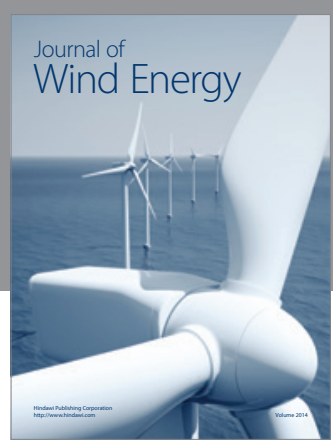

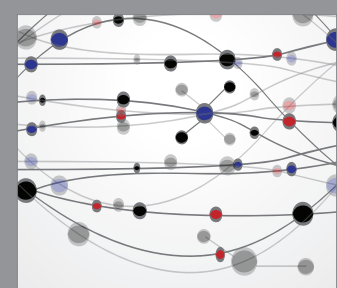

The Scientific World Journal

Submit your manuscripts at http://www.hindawi.com

Journal of

Structures
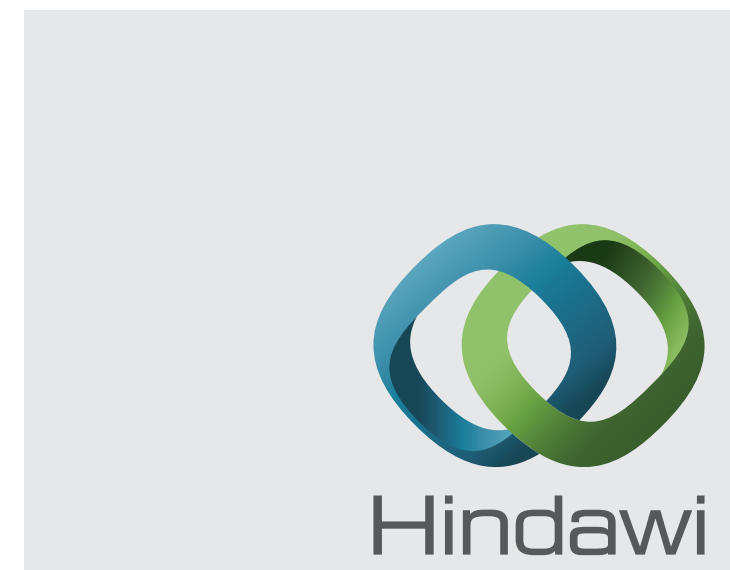

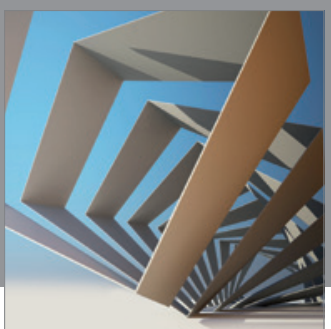

Rotating

Machinery
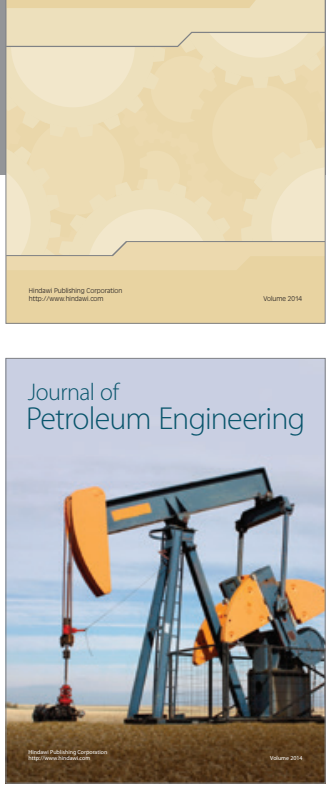

Journal of

Solar Energy
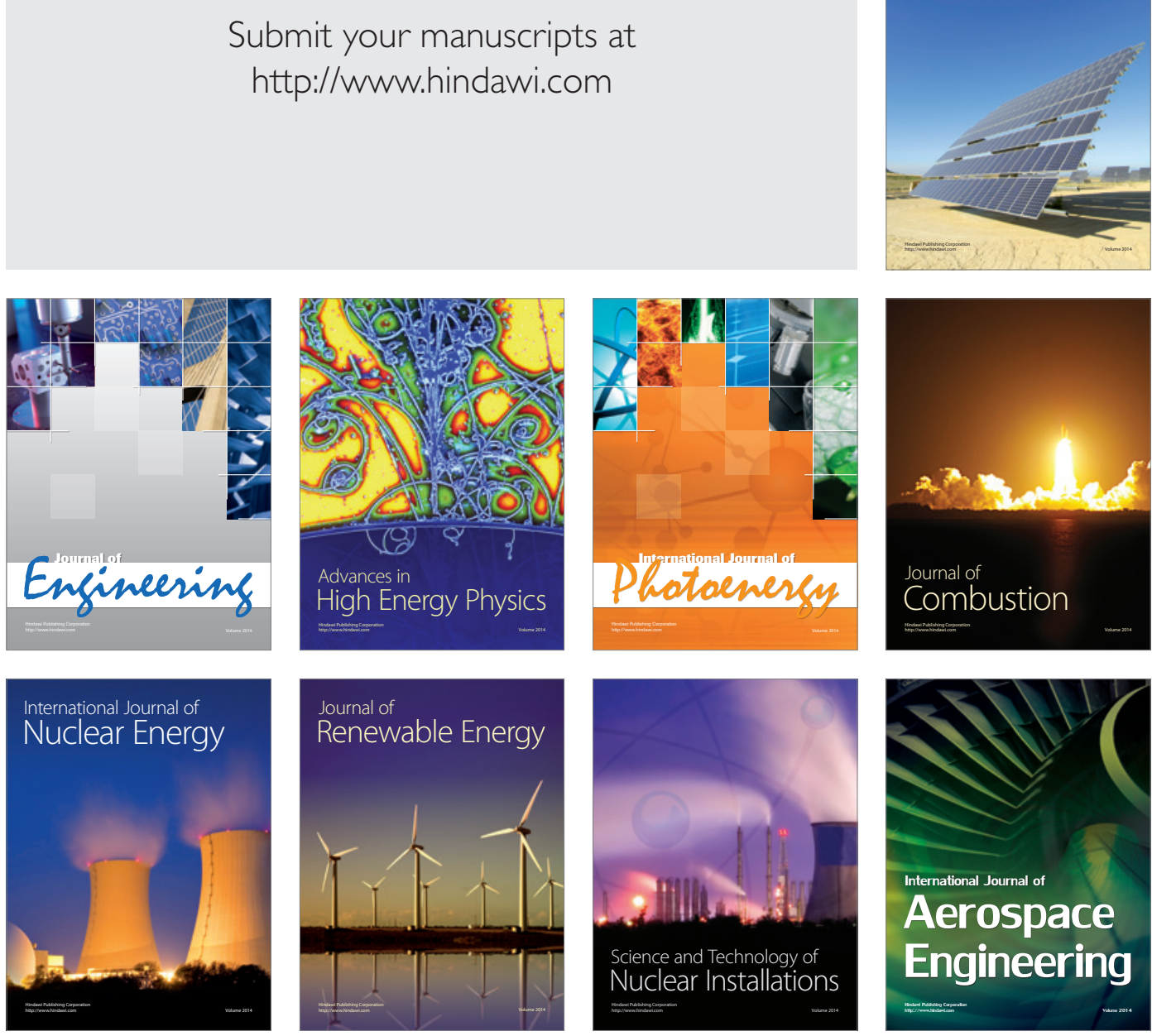